|| ISSN(online): 2589-8698 || ISSN(print): 2589-868X ||

International Journal of Medical and Biomedical Studies

Available Online at www.ijmbs.info

NLM (National Library of Medicine ID: 101738825)

Index Copernicus Value 2018: 75.71

Original Research Article

Volume 4, Issue 6; June: 2020; Page No. 106-110

\title{
COLOR DOPPLER ULTRASONOGRAPHY FINDINGS IN KIDNEY ALLOGRAFTS BEFORE AND AFTER
} TRANSPLANTATION

Dr. Suraj Mathur ${ }^{1}$ (Senior Resident), Dr. P. Rajan ${ }^{2}$ (Prof.) \& Dr. Jaya Kumar E.K ${ }^{3}$ (Assoc. Prof.)

Department of Radio Diagnosis, Govt. Medical College, Kozhikode, Kerala, India ${ }^{1 \& 2}$

Department of Nephrology, Govt. Medical College, Kozhikode, Kerala, India ${ }^{3}$

Article Info: Received 03 May 2020; Accepted 15 June 2020

DOI: https://doi.org/10.32553/ijmbs.v4i6.1210

Corresponding author: Dr. P. Rajan

Conflict of interest: No conflict of interest.

\section{Abstract}

Method: A sample size of 40 kidney allograft recipients undergoing color Doppler Ultrasonography evaluation included in the study.

Result: Corticomeduallry differentiation of kidney allografts within 24 hours post transplant period: There was no significant difference between CMD of kidney allorgrafts with complication and kidney allografts without any complication within 24 hour because the standard deviations of both groups were 0 . Corticomeduallry differentiation in all kidney allografts, all were shows maintained corticomedullary differentiation.

Conclusion: This study is aimed to assessing the role of CDUS in kidney allograft recipients to evaluate the graft perfusion immediate after anastamosis, within 24 hours and follow up period after engraftment of kidney allograft. Analyse the Color Doppler Ultrasound (CDUS) indices changes in parenchymal, and vascular cause of allograft dysfunction at follow up periods, to evaluate the uroloical, surgical and vascular complications in kidney recipients by using gray scale and color Doppler US at follow up periods and compare the results with biochemical parameter (serum creatinine).

Immediate Doppler ultrasound is highly useful in the diagnosis of primary graft dysfunction and in follow-up of the transplanted patient.

Keywords: Graft Perfusion, Anastamosis, Color, Doppler, Ultrasound

\section{Introduction}

The kidneys are the main organs of the urinary system. They function chiefly to filter blood in order to remove wastes and excess water. The waste and water are excreted as urine. The kidneys also reabsorb and return to the blood needed substances, including amino acids, sugar, sodium, potassium, and other nutrients ${ }^{1}$. Common causes of acute renal failure include; heart attack, illegal drug use and drug abuse, not enough blood flowing to the kidneys, and Urinary tract problems etc. Common cause of end-stage renal disease are diabetes, high blood pressure, Autoimmune diseases, such as lupus and IgA nephropathy, genetic diseases (diseases you are born with), such as polycystic kidney disease, nephrotic syndrome, etc.

The renal-urologic system includes two kidneys, two ureters, a urinary bladder, and the urethra. The normal adult kidney is bean-shaped and is located retroperitoneally between the level of the $12^{\text {th }}$ thoracic and third lumbar vertebrae. The right kidney lies slightly lower than the left because of displacement by the liver. The left kidney is slightly longer than the right and lies closer to the midline $e^{2}$. The ureters are tubes that measure from 27 to $30 \mathrm{~cm}$ long and are approximately 1 to $5 \mathrm{~mm}$ in diameter. They extend from the kidneys to the bladder.

Enclosed by a fibrous capsule, the kidney's functional elements consist of an outer cortex and an inner renal medulla. The medulla is divided into a series of wedges, called the renal pyramids, open into the renal calyces. The major calyces join to form the renal pelvis, an extension of the upper end of the ureter. Renal columns extend from the cortex down between the renal pyramids.

The kidney's basic work units are the nephrons. Approximately 1.2 million nephrons are contained in each kidney and form the urine. Each nephron consists of the Bowman's capsule that surrounds the glomerular capillary tuft, the proximal convoluted tubule, the loop of Henle, and the distal convoluted tubule, which empties into the collecting ducts. Urine formation begins in the cortex and continues flowing through the tubules and collecting ducts. The formed urine then flows into the papillary ducts of Bellini, enters the calyces and renal pelvis, and finally exits the kidney through the ureter to the bladder. ${ }^{3}$ 


\section{Material \& Method}

Study conducted at Department of Radiology and Department of Nephrology, Government Medical College and Hospital, Kozhikode, Kerala from May 2016 to October 2017.

\section{Inclusion criteria:}

Kidney Allograft recipients and donor with informed consents, undergoing Color Doppler ultrasound evaluation will be included in the study.

\section{Exclusion criteria:}

Kidney allograft recipients who was not willing to participation in this study.

\section{Sample size:}

A sample size of 40 kidney allograft recipients undergoing color Doppler ultrasonography evaluation included in the study. Approximately one kidney allograft is done per week in Government Medical College and Hospital Kozhikode, Kerala.

Source population: Live related kidney allograft recipients in the Department of Nephrology, government medical college and hospital, Kozhikode included in the study.

\section{Study Method and procedure:}

1. A hospital based study with informed consent in Malayalam and English language.

2. Following data collected from recipients and donor Basic data and information, general condition, blood pressure and daily urine output, biochemical parameter i.e. serum creatinine by using a proforma.

3. The following parameters evaluated by CDUS and gray scale US in recipients and donor - Size of allograft kidney, resistive index, pulsatility index, corticomedullary difference, and renal cortical echoes during pre transplant to follow up periods by using a proforma.

4. After transplantation, the patients were divided into two groups on the basis color Doppler ultrasound and biochemical values (serum creatinine) (I) normal kidney allograft without any complication and (II.) kidney allograft with complications i.e. acute pathology (ATN, acute rejection, renal artery thrombosis, and cyclosporine intoxication,), lymphocele, urinoma, seroma, HUN and renal artery stenosis .

5. The first examination as baseline is done two days before transplantation in donor. Then the recipients were evaluated within $24 \mathrm{hrs}$ post transplant, at the end of first week of post transplant, at the end of second week (before discharge) of post transplant, and 3 months after the post transplant.

\section{Acute rejection allograft}
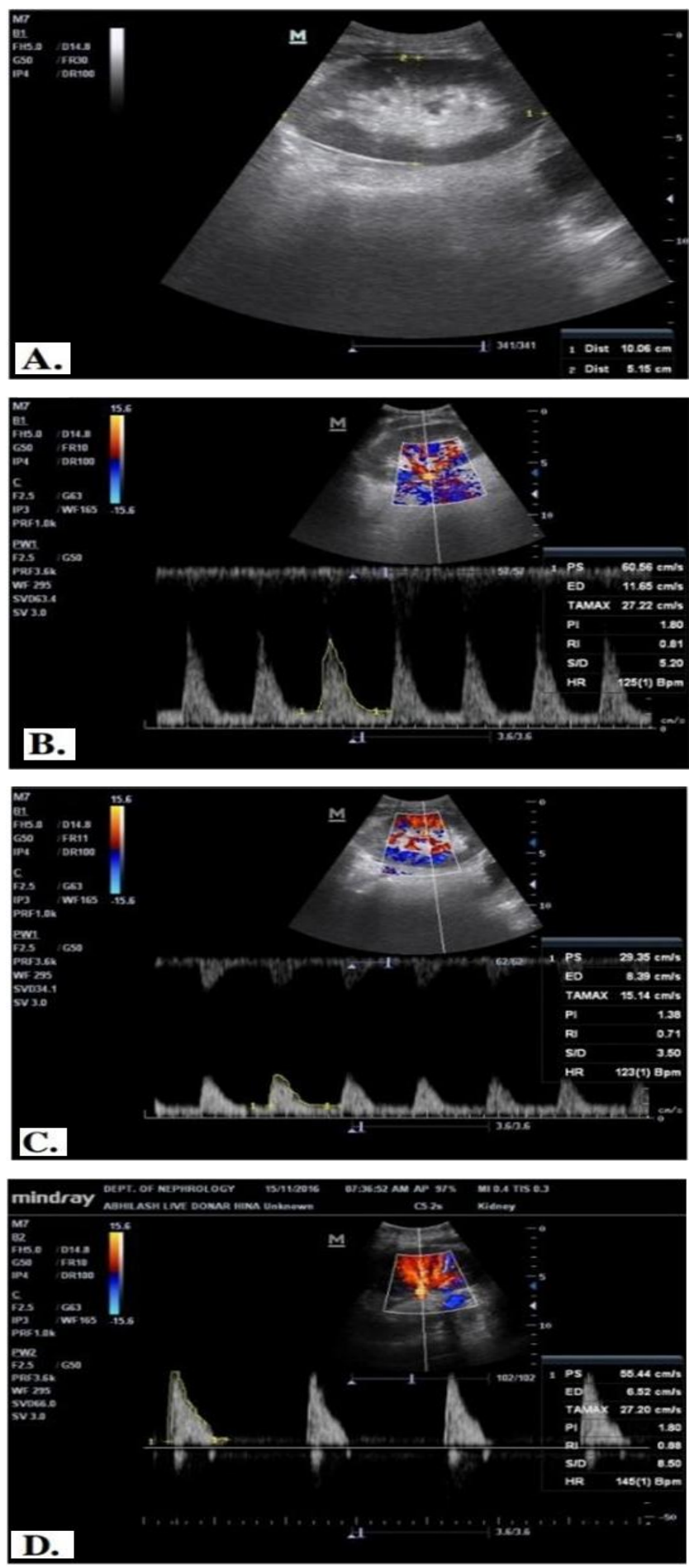

Figure 1: A. Shows normal size kidney with increased cortical echogenicity and few small hypoechoic area also seen in cortex. B to $\mathbf{C}$ at Doppler indices at the renal hilum and interlober region appears elevated (R.I.> .70 and P.I. > 1.3. D. Another case of rejection with absent diastolic flow 


\section{Urinoma}
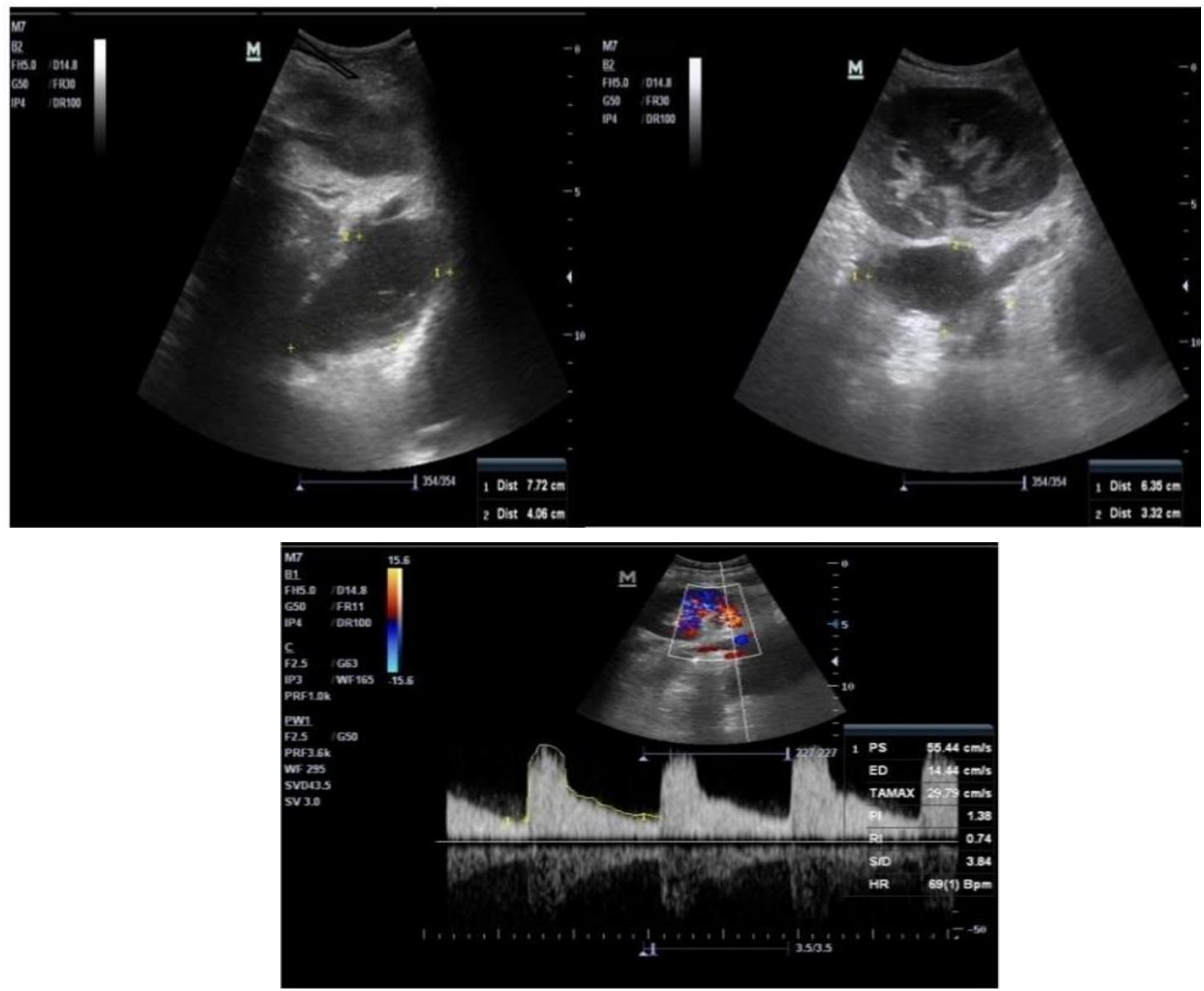

Figure 2: Show nechoic collection with thin septations around perinephric location with increased (R.I. >.70 and P.I. >1.3)

\section{Results}

Table 1: Size of kidney allografts within 24 hours

\begin{tabular}{lllll}
\hline Allografts & Size & Mean & No. of allogrfats & Std. deviation \\
\hline With complication & Normal & 1.000 & 3 & 0.0000 \\
\hline Without complication & Normal & 1.000 & 37 & 0.0000 \\
\hline Total & & & 40 & 0.0000 \\
\hline
\end{tabular}

Corticomeduallry differentiation of kidney allografts within 24 hours post transplant period: There was no significant difference between CMD of kidney allorgrafts with complication and kidney allografts without any complication within 24 hour because the standard deviations of both groups were 0 . Corticomeduallry differentiation in all kidney allografts, all were shows maintained corticomedullary differentiation.
Table 2: Corticomeduallry differentiation (CMD) within 24 hours

\begin{tabular}{lllll}
\hline Allografts & CMD & Mean & No. of allogrfats & $\begin{array}{l}\text { Std. } \\
\text { deviation }\end{array}$ \\
\hline With complication & Maintained & 1.000 & 3 & 0.0000 \\
\hline $\begin{array}{l}\text { Without } \\
\text { complication }\end{array}$ & Maintained & 1.000 & 37 & 0.0000 \\
\hline Total & & & 40 & 0.0000 \\
\hline
\end{tabular}

Cortical echogenicity of kidney allografts within 24 hours post transplant period: There were no significant difference between mean value of echogenicity in kidney allorgrafts with complication and kidney allografts without any complication within 24 hour post transplant period because $p$ value is 0.81 . Out 40 kidney allografts 37 normal kidney allografts shows normal cortical echogenicity and 3 complicated kidney allografts shows increased cortical echogenicty. 
Table 3: Cortical Echogenicity of kidney allografts within 24 hours

\begin{tabular}{lllll}
\hline Allografts & $\begin{array}{l}\text { Cortical } \\
\text { echogenicity }\end{array}$ & Mean & $\begin{array}{l}\text { No of } \\
\text { allogrfats }\end{array}$ & $\begin{array}{l}\text { Std. } \\
\text { deviation }\end{array}$ \\
\hline $\begin{array}{l}\text { With } \\
\text { complication }\end{array}$ & Increased & 1.3333 & 3 & .57735 \\
\hline $\begin{array}{l}\text { Without } \\
\text { complication }\end{array}$ & Normal & 1.0541 & 37 & .22924 \\
\hline Total & & & 40 & \\
\hline
\end{tabular}

\section{$P$ value-0.81}

Resistive index in kidney allografts within $\mathbf{2 4}$ hours post transplant: There were significant difference between mean value of resistive index in kidney allorgrafts with complication and kidney allografts without any complication within 24 hour post transplant periods because $p$ value is 0.026 .

Table 4: Resistive index kidney allografts within 24

\begin{tabular}{llll}
\hline Allografts & $\begin{array}{l}\text { No. } \\
\text { allogrfats }\end{array}$ & $\begin{array}{l}\text { of } \\
\text { R.I. }\end{array}$ & $\begin{array}{l}\text { Mean } \\
\text { R.l. deviation }\end{array}$ \\
\hline With complication & 3 & .7467 & 0.3786 \\
\hline Without complication & 37 & .6714 & 0.5498 \\
\hline Total & 40 & & \\
\hline
\end{tabular}

\section{$P$ value -0.026}

Pulsatility index in kidney allografts within $\mathbf{2 4}$ hours post transplant: There were significant difference between mean value of pulsatility index in kidney allorgrafts with complication and kidney allografts without any complication within 24 hour post transplant periods because $p$ value is 0.010 .

\section{Discussion}

Along with kidney transplantation, research has been focused on noninvasive diagnostic techniques for complications, such as urological complications, surgical and vascular complications ${ }^{5}$. These methods reliably predict the outcomes of transplantation and renal function after transplant revascularization. The Doppler has steadily improved over the last 5 years; it is now frequently used as the first-line screening test for patients with kidney transplantation. It is not only a useful tool in early evaluation of possible graft insufficiency, but also a reliable, noninvasive, and readily available tool to identify subjects who may benefit from kidney graft revascularization ${ }^{6}$.

In our study we evaluated 40 living kidney allograft recipients by using Color Doppler ultrasonograpgy and gray scale sonography in which $31(77.5 \%)$ were males and 9 $(22.5 \%)$ were females with a male to female ratio of 3.4:1. Majority of the recipients belonged to the age group of 20 -29 years (37.5\%). Routinely, total 40 living donor kidney evaluated in donor two days before the transplant ${ }^{7}$. Total
40 kidney allograft recipients evaluated within 24hours of post transplant, at the end of 1st week of post transplant and at the end of 2 nd week of post transplant. 3 months after follow up of post transplant only $21(52.5 \%)$ kidney allograft recipients evaluated in which 15 (71.4\%) were male and $6(28.6 \%)$ were female.

In this study we measured the size of kidney allograft, cortical echogenicity, corticomedullary differentiation, resistive index (R.I.), (P.I.) and serum creatinine value. Doppler indices correlation with the serum creatinine in kidney allografts without complication and kidney allografts with the complication ${ }^{8}$.

Gary scale ultrasonography and color Doppler findings within 24 hour to 3months after the post transplant periods. Within 24 hours of post transplant, in which $92.5 \%$ (37) were normal kidney allografts without any complication and $7.5 \%$ (3 recipients) kidney allograft with complication. Out of $7.5 \%$ (3 recipients), 5\% (2 recipients) were found acute rejection (biopsy proved ATN), 2.5\% (1 recipient) were found perinephric collection ${ }^{9}$.

Total 21 kidney allografts were evaluate after 3 months of post transplant period by the gray scale US, in which $61.9 \%$ (13 recipients) have normal renal allografts without any complication, and $38.1 \%$ ( 8 recipients) with complication in which, 9.5\% (2 recipients) were found perinephric urinoma, in $14.3 \%$ ( 3 recipients) were found acute rejection of kidney allografts (biopsy proved ATN) , in $9.5 \%$ ( 2 recipient) were found renal artery stenosis (RAS) and in $4.8 \%$ (1 recipients) were found hydroureteronephrosis $(\mathrm{HUN})^{10}$.

\section{Conclusion}

This study is aimed to assessing the role of CDUS in kidney allograft recipients to evaluate the graft perfusion immediate after anastamosis, within 24 hours and follow up period after engraftment of kidney allograft. Analyse the Color Doppler Ultrasound (CDUS) indices changes in parenchymal, and vascular cause of allograft dysfunction at follow up periods, to evaluate the uroloical, surgical and vascular complications in kidney recipients by using gray scale and color Doppler US at follow up periods and compare the results with biochemical parameter (serum creatinine).

Immediate Doppler ultrasound is highly useful in the diagnosis of primary graft dysfunction and in follow-up of the transplanted patient.

\section{References}

1. Akbar SA, Jafri SZH, Amendola MA, Madrazo BL, Salem R, Bis KG. Complications of Renal Transplantation. Radiographics 2005; 25:1335-1356. 
2. Drudi FM, Liberatore M, Cantisani V, et al. Role of color Doppler ultrasound in the evaluation of renal transplantation from living donors. Journal of ultrasound 2014;17:207-213.

3. Wallace MA. Anatomy and Physiology of the Kidney. AORN J 1998;68:799-820.

4. Irshad A, Ackerman S, Sosnouski D, Anis M, Chavin K, Baliga P. A review of sonographic evaluation of renal transplant complications. Curr Probl Diagn Radiol 2008;37:67-79.

5. Sharfuddin A. Renal relevant radiology: imaging in kidney transplantation. Clin J Am Soc Nephrol 2014;9:416-429.

6. Enhesari A, Mardpour S, Makki Z, Mardpour S. Early Ultrasound Assessment of Renal Transplantation as the Valuable Biomarker of Long Lasting Graft Survival: A Cross-Sectional Study. Iranian Journal of Radiology 2014;11:e11492.
7. Shakeri Bavil A, Mirfakhraei A, Tayebi Khosroshahi $H$, Chokhachizadeh Moghadam R, Fouladi DF. The inability of an early post-transplantation intrarenal resistive index to predict renal allograft function at 12 weeks after engraftment in young adults. Acta Radiol 2015;57:1402-1408.

8. Gordon EJ, Ladner DP, Caicedo JC, Franklin J. Disparities in Kidney Transplant Outcomes: A Review. Semin Nephrol 2010;30:81.

9. Lafranca JA, ljermans JNM, Betjes MGH, Dor FJMF. Body mass index and outcome in renal transplant recipients: a systematic review and meta-analysis. BMC Med 2015;13:111.

10. Torpy JM, Lynm C, Golub RM. Kidney transplantation. JAMA 2011; 305:634-634. 